\title{
Chemichal Caracterisation of Essential Oil for Saturea Montana Population from Burreli Area, Albania
}

\author{
Jonida Salihila and Aurel Nuro*
}

Department of Chemistry, Faculty of Natural Sciences, University of Tirana, Albania

\section{Article Info}

\section{*Corresponding author:}

Aurel Nuro

Department of Chemistry

Faculty of Natural Sciences

University of Tirana

Albania

Email: aurel.nuro@fshn.edu.al

\section{Received: August 31, 2018}

Accepted: September 21, 2018

Published: September 27, 2018

Citation: Salihila J, Nuro A. Chemichal Caracterisation of Essential Oil for Saturea Montana Population from Burreli Area, Albania. Madridge J Anal Sci Instrum. 2018; 4(1): 88-91.

doi: $10.18689 / \mathrm{mjai}-1000117$

Copyright: ( 2018 The Author(s). This work is licensed under a Creative Commons Attribution 4.0 International License, which permits unrestricted use, distribution, and reproduction in any medium, provided the original work is properly cited.

Published by Madridge Publishers

\begin{abstract}
This study presents data on the chemical analysis of essential oil for the Saturea Montana plant population from the Burreli area (Central Albania). Saturea Montana is the native variety in the Mediterranean region, though it is adapted and spread in many countries around the world. It has a long history of medical and culinary use, as well as a decorative garden plant. It has a long history of medical and culinary use, as well as a decorative garden plant. During herbs collection, two factors were identified which describe the natural conditions of their growth; lands with differences in their composition (red soil and black soils) and in the height of 600 to $1000 \mathrm{~m}$, with the aim of influencing these factors in the composition of their essential oil. The dried plants in the air were cut into small pieces $(1-2 \mathrm{~cm})$ and then subjected to a European Pharmacopoeia (Clevenger type) for a period of 4 hours to extract essential oil from Saturea Montana. The chemical composition of essential oils is analyzed using the GC / FID technique. Each Saturea Montana sample extract was injected into a Varian 450 GC. For the separation of compounds, capillary columns VF- $1 \mathrm{~ms}(30 \mathrm{~m} \times 0.33 \mathrm{~mm} \times 0.25 \mu \mathrm{m})$ were used. p-Cymene, Linalool, Thymol and Carvacrol were identified as the main constituents in all the analyzed essential oils of Saturea Montana samples obtained from the Burrel area. Their concentrations are in the range of 25 to $50 \%$, and this fact is mainly related to the geographic position of the samples and the time of sampling.
\end{abstract}

Keywords: Saturea Montana; Essential Oils; p-Cimene; Linalool; Timol; GC/FID.

\section{Introduction}

Saturea montana is a semi-green perennial herb that is part of the Lamiaceae family, which are native plants of warm, temperate regions of southern Europe, the Mediterranean and Africa. They can be found in all areas of Albania [1]. Saturea Montana is easy to grow and is found in every culinary herb garden. The main growth conditions are six hours of sunshine per day and a well drained agricultural land. In mild climate, this plant dries and blooms again in the spring. It can grow and it is found in old walls, on dry docks and rocks on hillsides or on rocky mountain slopes. It is found most often in limestone or alkaline soils. Saturea Montana has dark green leaves and flowers ranging from pale lavender to pink or white. Its length extends between $10 \mathrm{~cm}$ and 40 $\mathrm{cm}$. The color of the skin is dark green and the leaves are opposite, oval-lanceolate with their length of $1-2 \mathrm{~cm}$ and their width of $5 \mathrm{~mm}$. The flowers appear in the summer, between July and October, and have a color that varies from pale lavender, or red to white [2-3]. There is historical evidence of its use about 2000 years ago by ancient Romans and Greeks. Its aroma is very strong and can be added both in bread cooking, as well as cooking various meat and trout fish. It is assumed that Saturea Montana possesses antiseptic, aromatic, carminative and digestible properties. Also, it has been used as an expectorant in treating bee bites, or insect bites, using a poultice of the 
leaves. It is used for remedy for colic and a cure for flatulence, whilst it is also used to treat gastro-enteritis, cystitis, nausea, diarrhoea, bronchial congestion, sore throat and menstrual disorders. It should not be used by pregnant women, unless it is not precribed by these cases.

In general, the plant is harvested in summer, a period in which the flowers can be used fresh or dried. The essential oil forms an ingredient in lotions that are used in the treatment of incipient baldness scalp. The main ingredients, which are Carvacrol / Thymol, define a strong spicy flavor of plants. They exhibit a significant antioxidant potential, while Linalool or Geraniol have a lower activity. The essential oil of Saturea Montana contains antioxidative compounds such as: Carvacrol, Thymol, beta-Caryophyllene, alfa-Terpinene, p-Cymeneand Linalool [4-6]. Therapeutic-grade oil has been determined to inhibit growth of Candida albicans. In traditional herbal medicine, it was believed that Saturea Montana prevented sexual desire.

\section{Materials and Methods}

\section{Reagent and Standards}

Toluene of chromatographic grade was purchased from Merck (Darmstadt, Germany). Calculation of Kovats' Indicators (KI) was performed using a mixture of $n$-alkanes (Sigma Aldrich) from n-octane (C8) to eicosane (C20).

\section{Sample Collection of Saturea Montana from Burreli Area in Albania}

The Saturea montana samples were taken from the Burrel area, located in Central Albania. Saturea montana plants were selected in June 2017. The harvested plants are grown on redcolored agricultural land (SM1-SM6) and black-colored agricultural land (SM7-SM9), with the purpose of studying the changes of essential oil in each case. Also, the plant collection process was carried out at different geographic elevations, varying from 600 to $1000 \mathrm{~m}$ above sea level. Various morphological parts (such as the stubble, leaves and flowers) of Saturea montana are used for this study. Drying of herbal material was carried out in the air and in the shade, making possible the preservation of their morphological characteristics.

\section{Saturea Montana Essential Oil Isolation Process}

The Saturea montana air dried material was cut into small pieces $(1$ to $2 \mathrm{~cm}$ ) before it was analyzed. An amount of $50 \mathrm{~g}$ of dried herbal material was distilled with water vapor for a period of 4 hours, using a modified Clevenger type apparatus to produce essential oil of the plant. A volume of $1 \mathrm{ml}$ of toluene is added to the distillation balloon for the isolation of essential oils from Saturea Montana. Essential oil is dried using anhydrous sodium sulphate (Na2SO4) and kept sealed in dark glass vial at a temperature of $+4 \mathrm{oC}$ until use. Diluted essential oil in Toluene was used for GC/FID analyses.

\section{Apparatus and Chromatography}

Gas chromatographic analyses of Saturea montana essential oil were realized using a Varian 450 GC instrument equipped with a flame ionization detector and PTV detector. The injector temperature of the PTV was set at $280^{\circ} \mathrm{C}$. The volume of 1 liter of essential oil Saturea montana, which is diluted in Toluene, was injected in splitless mode. The FID Detector temperature was held at $280^{\circ} \mathrm{C}$. Nitrogen was used also as carrier with a flow of $1 \mathrm{ml} / \mathrm{min}$, as well as make-up gas with a flow of $25 \mathrm{ml} / \mathrm{min}$. Hydrogen and air were used as flame detector gases with flow rates of $1 \mathrm{ml} / \mathrm{min}$ and $25 \mathrm{ml} /$ min, respectively. VF-1ms capillary column (30 m x $0.33 \mathrm{~mm} \times$ $0.25 \mu \mathrm{m}$ ) was used to isolate compounds of Saturea Montana essential oil. The oven temperature was programmed in the following steps: the furnace temperature was increased to 40 ${ }^{\circ} \mathrm{C}$ and maintained for 2 minutes, then increased to a temperature of $150{ }^{\circ} \mathrm{C}$ with an increase rate of $4{ }^{\circ} \mathrm{C} / \mathrm{min}$. Subsequently, the temperature rise continues to $280^{\circ} \mathrm{C}$ with an increase rate of $10{ }^{\circ} \mathrm{C} / \mathrm{min}$ and is maintained at this temperature for 2 minutes. The identification of the compounds was based on comparison of their Kovats indices $(\mathrm{KI})$, their retention times (RT) and literature [7-10].

\section{Results and Discussions}

The essential oil of the Saturea montana samples from the Burrel area, Central Albania was analyzed using the GC / FID technique. In this study are presented the average values of the results obtained for samples from the same areas. Data is expressed as a percentage of total peak by removing the toluene peak, which was the solvent used for dilution.In the essential oils of Saturea montana 40 to 60 compounds were found. Table 1 shows the data for the 22 major components found in Saturea montana essential oil samples by analyzing them by chromatographic methods. Peaks with percentages smaller than $0.1 \%$ are not presented. Also, in this table are given the quantities calculated for monoterpenes and sesquiterpenes. In Figure 1 there are given terpenic dispersions according to respective classes and in Figure 2 are given the individual profiles of the terpenes. The total amount of 22 main compounds varies from $80.2 \%$ for the SM6 sample to $97.2 \%$ for the SM2 sample, as shown in Table 1. Their average value is $93.7 \%$. The lowest percentage value that is obtained for the SM6 sample is related to the presence of other terpenes in essential oil, except for the 22 major compounds that make up the main matrix of the analyzed samples. The terpene distribution given in Figure 1 was the same for all analyzed samples of Saturea montana of the Burrel area because of the same origin. Differences between samples may be caused by the change in geographic elevation and geological composition of the lands where the plants have grown. Samples from SM1 to SM6 are found in red soil, and in geographic elevations extending from $610 \mathrm{~m}$ to $1007 \mathrm{~m}$ above sea level. Samples SM7*, SM8* and SM9* were found on black soils at altitudes from $675 \mathrm{~m}$ to $970 \mathrm{~m}$ above sea level. Sample SM6 was sampled at the station with the highest geographic elevation. The altitude may be the main factor affecting the essential oil composition. Terpenes that were found in higher percentage were: p-Cymene, Linalool, Thymol and Carvacrol, as shown in Figure 2. Note that the profile of these compounds was not the same for all the samples studied. p-Cymene was found in 
the highest percentage in almost all samples except in the SM3 sample. The lowest percentage of $6.9 \%$ was found in the SM3 sample and the highest percentage value of $35.1 \%$ was found in the SM4 sample. Linalool was the second compound with the highest percentage for the largest number of samples. Its percentage varies from $1.1 \%$ found in the SM4 sample up to $22.32 \%$ found in the SM3 sample and the opposite is found for $\mathrm{p}$-Cymene. Carvacrol Percentage, which is found in the SM1, SM6, SM8 * and SM9 samples. was higher than the percentage of Thymol found in these samples. The total percentage of Carvacrol and Thymol compounds is higher for samples found in red soil. Samples found in black soil have a higher percentage of Borneol, Methyl ether Carvacrol, betaCaryophyllene, Caryophyllene and Alpha-Humulene. SM6 and SM3 samples have been found to have higher percentages of monoterpene compounds ranging from $65.0 \%$ to $90.5 \%$. The aromatic monoterpenes, p-Cymene, Thymol, Carvacrol, Thermol methyl ether and methylcarvacrol ether are found at a higher percentage compared to other compounds, ranging from $30.1 \%$ to $66.5 \%$. These Saturea montana essential oils can be classified as a phenolic type because of the relatively high levels of Thymol and Carvacrolt. Oxygen monoterpenes, such as Cineole, Linalool, Borneol, Kamfori, Terpinen-4-ol and Terpineol, are the second major group found in Saturea montana samples, with the exception of the SM8 sample, where they are the first group of components the highest percentage.

Table 1. Percentage data of the main components in the analyzed samples of Saturaa Montana Essential Oil

\begin{tabular}{|c|c|c|c|c|c|c|c|c|c|}
\hline & SM1 & SM2 & SM3 & SM4 & SM5 & SM6 & SM7* & (SM8* & SM9* \\
\hline alfa-Pinene & 1.51 & 1.23 & 0.21 & 3.45 & 4.17 & 4.82 & 5.02 & 3.93 & 3.61 \\
\hline Camphene & 2.91 & 1.50 & 0.26 & 3.57 & 7.39 & 1.16 & 0.74 & 0.93 & 0.89 \\
\hline beta-Pinene & 2.44 & 3.43 & 1.12 & 1.43 & 3.53 & 2.75 & 3.02 & 0.41 & 0.35 \\
\hline Myrcene & 0.27 & 1.53 & 0.10 & 1.61 & 0.16 & 2.26 & 2.53 & 0.69 & 0.58 \\
\hline para-Cymene & 20.86 & 23.86 & 6.88 & 35.10 & 14.13 & 17.55 & 17.79 & 16.95 & 14.62 \\
\hline Limonene & 1.86 & 5.62 & 0.81 & 1.57 & 10.63 & 3.62 & 3.61 & 3.74 & 3.32 \\
\hline Cineole & 1.51 & 1.35 & 0.20 & 0.10 & 1.94 & 1.40 & 1.41 & 1.28 & 1.10 \\
\hline gama-Terp & 9.05 & 5.23 & 2.80 & 3.39 & 2.44 & 1.43 & 2.41 & 0.11 & 1.09 \\
\hline Linalool & 12.50 & 14.23 & 22.32 & 1.10 & 11.07 & 9.89 & 10.15 & 19.79 & 16.29 \\
\hline Camph & 1.79 & 1.27 & 0.40 & 1.99 & 1.48 & 4.30 & 4.32 & 1.02 & 0.43 \\
\hline Borneol & 11.21 & 1.19 & 8.60 & 1.99 & 4.07 & 1.07 & 1.02 & 12.72 & 10.64 \\
\hline Terpinen-4-ol & 6.00 & 1.24 & 0.10 & 1.19 & 2.49 & 1.55 & 1.58 & 1.88 & 1.52 \\
\hline alfa-Terpineol & 0.76 & 0.23 & 0.11 & 0.18 & 1.29 & 0.67 & 0.94 & 1.75 & 1.15 \\
\hline Thymol methyl ether & 0.63 & 2.33 & 2.82 & 1.03 & 0.98 & 0.96 & 0.45 & 1.37 & 0.34 \\
\hline Carvacrol m & 1.64 & 1.32 & 2.70 & 1.73 & 1.66 & 0.39 & 0.12 & 3.64 & 3.08 \\
\hline Thymol & 2.77 & 14.22 & 24.54 & 26.11 & 9.08 & 3.17 & 14.23 & 4.68 & 9.31 \\
\hline Carvacrol & 12.48 & 10.45 & 16.49 & 2.48 & 5.62 & 8.04 & 12.25 & 9.59 & 15.96 \\
\hline beta-Caryophyllene & 1.78 & 2.71 & 1.21 & 3.25 & 1.54 & 4.89 & 4.28 & 3.34 & 2.92 \\
\hline alfa-Humulene & 0.21 & 0.23 & 0.20 & 0.93 & 1.91 & 2.51 & 2.74 & 1.09 & 1.88 \\
\hline beta-Bisabolene & 0.11 & 0.64 & 0.10 & 0.32 & 0.89 & 3.03 & 1.54 & 1.90 & 1.06 \\
\hline Cadinene & 0.43 & 0.33 & 0.50 & 0.32 & 1.96 & 1.48 & 0.54 & 0.78 & 1.75 \\
\hline Caryophyllene oxide & 2.42 & 3.01 & 3.90 & 4.20 & 6.28 & 3.22 & 3.12 & 2.98 & 2.35 \\
\hline Total & 95.15 & 97.15 & 96.37 & 97.04 & 94.71 & 80.16 & 93.81 & 94.57 & 94.24 \\
\hline Aliphatic Monoterpene & 0.27 & 1.53 & 0.10 & 1.61 & 0.16 & 2.26 & 2.53 & 0.69 & 0.58 \\
\hline Monocyclic Monoterpene & 10.91 & 10.85 & 3.61 & 4.96 & 13.07 & 5.05 & 6.02 & 3.85 & 4.41 \\
\hline Bicyclic Monoterpene & 6.86 & 6.16 & 1.59 & 8.45 & 15.09 & 8.73 & 8.78 & 5.27 & 4.85 \\
\hline Oxygenated Monoterpene & 33.77 & 19.51 & 31.73 & 6.55 & 22.34 & 18.88 & 19.42 & 38.44 & 31.13 \\
\hline Aromatic Monoterpene & 38.39 & 52.18 & 53.43 & 66.45 & 31.47 & 30.11 & 44.84 & 36.23 & 43.31 \\
\hline Total Monoterpene & 90.20 & 90.23 & 90.46 & 88.02 & 82.13 & 65.03 & 81.59 & 84.48 & 84.28 \\
\hline Sesquiterpene & 4.95 & 6.92 & 5.91 & 9.02 & 12.58 & 15.13 & 12.22 & 210.09 & 9.96 \\
\hline
\end{tabular}

One-cycle monoterpenes, such as Limonene and gammaTerpinene, were found with the highest percentages in SM1, SM2 and SM3 matrices sampled at 600-820 m above sea level, while bicyclic monoterpenes, such as Alpha-Pinene, Camphene and beta-Pinene were found at a higher percentage in the samples taken at altitudes from $850 \mathrm{~m}$ to $1000 \mathrm{~m}$ above sea level. The effect of height in these groups was evident. The growing process of plants may be different for different altitudes due to changes in air temperatures, sunny hours during one day, and so on. Aliphatic monoterpenes were found to be low in percentage.Percentages of sesquiterpenes, such as beta-Caryophyllene, alpha-Humulene, betabisphenol, cadincanum and Caryophyllene oxide vary by $5.0 \%$ for the SM1 sample up to $15.1 \%$ in the SM6 sample. Sesquiterpenes were found to be in a higher percentage in samples sampled on black soil and in samples found at altitudes greater than $700 \mathrm{~m}$. The height and composition of the soil can be above sea level. Height and composition of soils affect the percentage of these compounds in the essential oil of Saturea montana.

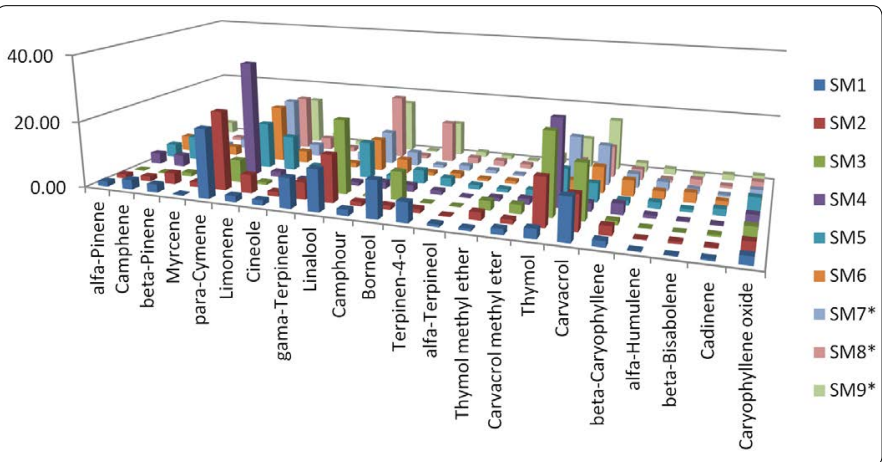

Figure 1. Distribution of terpenes in Saturea Montana essential oil samples

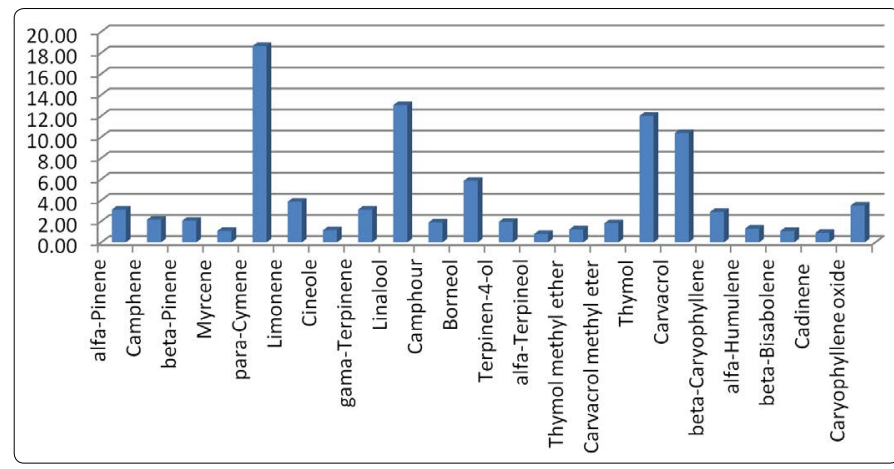

Figure 2. Profile of main compounds in analyzed Saturea Montana essential oil samples

\section{Conclusions}

The essential oils of Saturea montana found in Bulqiza, which is located in Central Albania, were analyzed using the GC / The data represent the percentages of the 22 major compounds found in all samples of Saturea montana essential oils. Samples SM1 to SM6 were sampled on red soil at altitudes from $610 \mathrm{~m}$ to 1007 above sea level, respectively. Samples SM7 *, SM8 * and SM9 * were found on black soils at altitudes from $675 \mathrm{~m}$ to $970 \mathrm{~m}$ above sea level. Terpenes that were found in a higher percentage were; $\mathrm{p}$-Cymene, Linalool, 
Thymol and Carvacrol. Note that their profile was not the same for all samples. $p$-Cymene was found to be the highest percentage for all samples. Linalool was the second high percentage compound for many of the samples and the opposite could be said for $\mathrm{p}$-Cymene. The total percentage of Carvacrol and Thymol were higher for samples found in reddish soils. Samples found in black soil have a higher percentage of Borneol, Methyl ether Carvacrol, betaCaryophyllene, Caryophyllene and Alpha-Humulene. Saturea Montana essential oil contains a high percentage of aromatic monoterpenes. The Saturea Montana essential oil can be classified as a phenolic type due to the high levels of Thymol and Carvacrol found. Sesquiterpenes are found to have a higher percentage for plant samples grown in black soil. Soil compositions and geographic position, especially geographic latitude, are the most important factors that affect the change in the composition of the essential oils of Saturea Montana. Profile and levels of compounds found in Central, South-East and South Albania Saturea Montana samples were comparable with the reported values of other studies conducted by authors of the Balkan and Mediterranean regions [4-11]. Work done in Burrel and other areas can be complete if it continues for several years.

\section{Conflict of Interest}

The author declares no conflict of interest.

\section{References}

1. Wolfgang $\mathrm{K}$, Susanne $\mathrm{H}$, Andreas H. Medicinal and Aromatic Plants in Albania, Bosnia-Herzegovina, Bulgaria, Croatia and Romania. A study of the collection of and trade in medicinal and aromatic plants (MAPs), relevant legislation and the potential of MAP use for financing nature conservation and protected areas. WWF Deutschland / TRAFFIC Europe-Germany. 2003.

2. Cavar S, Maksimovic M, Šolic ME, Jerkovic A, Bešta R. Chemical composition and antioxidant and antimicrobial activity of two Satureja essential oils. Food Chem. 2008; 111(3): 648-653. doi: 10.1016/j.foodchem.2008.04.033

3. Serrano C, Matos O, Teixeira B, Ramos C, Neng N, Nogueiro J, et al. Antioxidant and antimicrobial activity of Satureja montana extracts. J. Sci. Food Agric. 2011; 91(9): 1554-1560. doi: 10.1002/jsfa.4347

4. Sarac N, Ugur A. Antimicrobial activities and usage in folkloric medicine of some Lamiaceae species growing in Mugla, Turkey. Eurasian J Bio Sci. 2007; 4: 28-37.

5. Slavskovska V, Jancic R, Bojovic S, Milosavljevic S, Djokovic D. Variability of essential oils of Satureja montana L., and Satureja kitaibelii Wierzb. ex. Heuff. from the central part of the Balkan Peninsula. Phytochemistry. 2001; 57(1): 71-76.

6. Vidic D, Maksimovic M, Cavar S, Šolic ME. Comparison of essential oil profiles of Satureja montana L., and endemic Satureja visianii Šilic. Journal of essential oil-bearing plants JEOP. 2009; 12(3): 273-281. doi: 10.1080/0972060X.2009.10643720

7. Adams RP. Identification of essential oil components by gas chromatography/mass spectroscopy. Allured Publishing Cor-poration, Carol Stream: Illinois, USA. 1995.

8. David F, Scanlan F, Sandra P, Szelewski M. Analysis of essential oil compounds using retention time locked methods and retention time databases, Application. Agilent Technologies. 2010; 5988-6530.

9. Konig WA, Bulow N, Saritas Y. Identification of sesquiterpene hydrocarbons by gas phase analytical methods. Flavour Fragr. J. 1999; 14(6): 367-378. doi: 10.1002/(SICI)1099-1026(199911/12)

10. Bozin B, Mimica-Dukic N, Simin N, Anac-kov G. Characterization of the volatile composition of essential oils of some Lamiaceae spices and the antimicrobial and antioxidant activities of the entire oils. J. Agric. Food Chem. 2006; 54(5): 1822-1828. doi: 10.1021/jf051922u

11. Daferera DJ, Ziogas BN, Polissiou MG. GC-MS analysis of essential oils from some Greek aromatic plants and their fungitoxicity on Penicillium digitatum. Jour-nal of Agricultural Food Chemistry. 2000; 48(6): 25762581. 